\title{
Meroanencephaly in an English Pointer Neonate
}

\author{
Luísa Mariano Cerqueira da Silva', Helena Piúma Gonçalves ${ }^{2}$, Thaís Cozza dos Santos ${ }^{3}$, \\ Clarissa Caetano de Castro', Cristina Gevehr Fernandes', Fabiane Borelli Grecco', \\ Antonio Sergio Varela Junior ${ }^{4} \&$ Carine Dahl Corcini'
}

\begin{abstract}
Background: Malformations are structural or functional abnormalities in the organs and structures present at birth. These conditions are rarely described in the newborns of dogs and can lead to their death. Meroanencephaly is a defect of the neural tube closure malformation, a type of anencephaly and results from a failure of closure of the rostral neuropore (neural crest), and consequently the development of the calvary becomes defective. This study aims to characterize the clinical-pathological aspects of neonatal meroanencephaly since brain malformations are rare in newborn dogs.

Case: A 2-day-old English Pointer canine was sent for a necropsy. The newborn belonged to a litter of eight puppies, and only this one had macroscopic cranial alterations. Another puppy that died as a consequence of being trampled by the bitch was also necropsied. The newborn was alive for $48 \mathrm{~h}$ until death and presented apathy, crying, sucking reflex and opisthotonus. Macroscopic examination of the baby revealed flattening of the skull, with a slit at the site of bone symphysis fusion, and a slit in the skin of the parietal region, covered by thin, translucent meningeal tissue. The newborn had no other macroscopic changes. The heads of the two animals were examined by radiography to identify the features of anencephaly in one of the animals by visualizing skull bone flattening. Upon removing the skin and exposing the cranial cavity, an irregular reddish mass was revealed, that corresponded microscopically to area cerebrovasculosa, composed of neurons and rudimentary glial tissue, vascular neoformation and, hemorrhage and congestion. The cranial nerves was not possible to observe. There was disorganization of the brain areas with no limitation of white and gray matter and scarce neurons and also a region similar to the cerebellum, with a molecular layer but without the Purkinje neurons. In the spinal cord, scarce neuronal tissue and disorganization of gray and white matter were noticed.

Discussion: Meroanencephaly is a type of anencephaly, a congenital malformation originating from abnormal neurulation, which results from the absence of neural fold fusion during neural tube formation. Live-born anencephalics have some brainstem-driven functions such as spontaneous breathing and some reflex responses, for instance, suction. Several genetic or teratogenic factors, such as viruses, radiation, drugs administered during pregnancy and other pathologies transmitted from bitch to fetus, can lead to this defect. In veterinary medicine, data on teratogenic agents are scanty but it is believed that nutritional deficiencies are determining factors for the occurrence of such malformations, specially anencephaly and another neural tube defects, such as folic acid deficiency in humans. It is difficult to identify the real cause of the anencephaly, once the etiology is multifactorial in cranial and encephalic malformations. The reports on anatomopathological findings and the presence of area cerebrovasculosa are rare. Some other studies report anencephaly and meroanencephaly, but provide little data regarding macroscopic and especially microscopic findings. Pathological changes are not often described in neonates, since post mortem pathological examination is rarely requested, despite it can help to avoid and/or decreased the loss of neonates, and the possibility of infectious agents being involved in the lesions can be investigated.
\end{abstract}

Keywords: dogs, malformation, anencephaly, neural tube. 


\section{INTRODUCTION}

Congenital malformations affect the viability of newborns and may be caused by genetic factors or teratogenic agents during gestation [10]. Any anomaly that occurs in the prenatal period, from the blastocyst formation to the embryonic and fetal periods, can result in a congenital abnormality [7]. Genetic defects may occur due to consanguinity or genetic inheritance from one or both parents, being more common in purebred puppies $[1,10]$ due to inbreeding, since they intend to maintain racial patterns and inbreeding character fixation [6]. During the gestational period (about 63 days) newborns may be exposed to different factors such as irradiation, toxins, chemical agents, infectious diseases, mechanical influences, drugs given to the mother, nutritional deficiencies of vitamin A, vitamin $\mathrm{D}$, and folic acid [1,10,12].

Anencephaly is a malformation that belongs to the group of neural tube defects (NTD) [5] that occur in the embryonic period, which in the case of dogs is up to 35 days of gestation. Meroanencephaly is a classification among anencephaly, and results from failure to close the cranial end of the neural tube during neurocranial formation, indicating that part of the brain is present [8].

In this context, the objective of this work was to report a case of meroanencephaly in an English Pointer dog necropsied at the Serviço de Oncologia Veterinária SOVET - Patologia of Faculdade de Veterinária of UFPel, seeking to characterize the clinical-pathological aspects and to achieve a better understanding of these changes since they rarely occur in dogs.

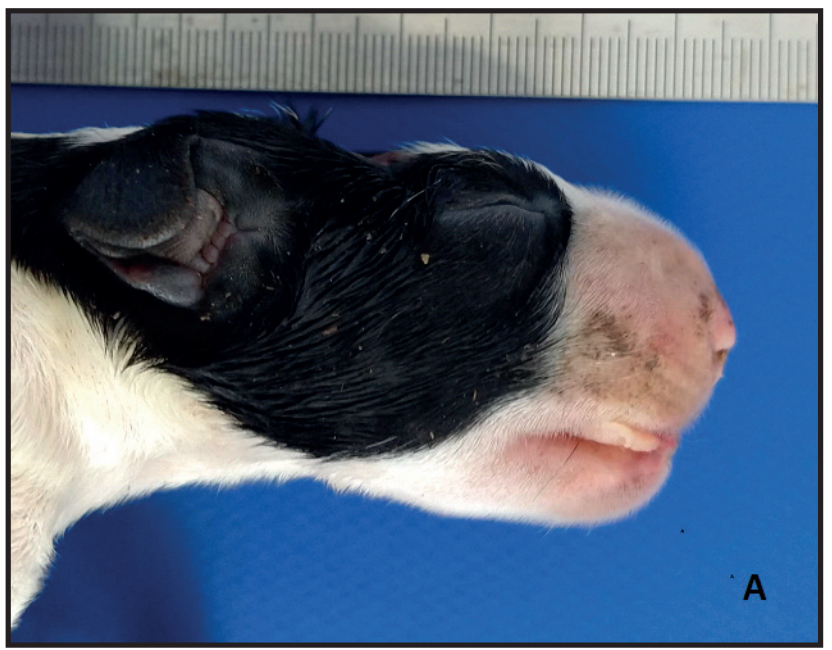

Figure 2. A- The neonate presenting cranial cavity opening and parietal bone flattening, dorsal view. B- The neonate presenting cranial cavity opening

and parietal bone flattening, right lateral view.

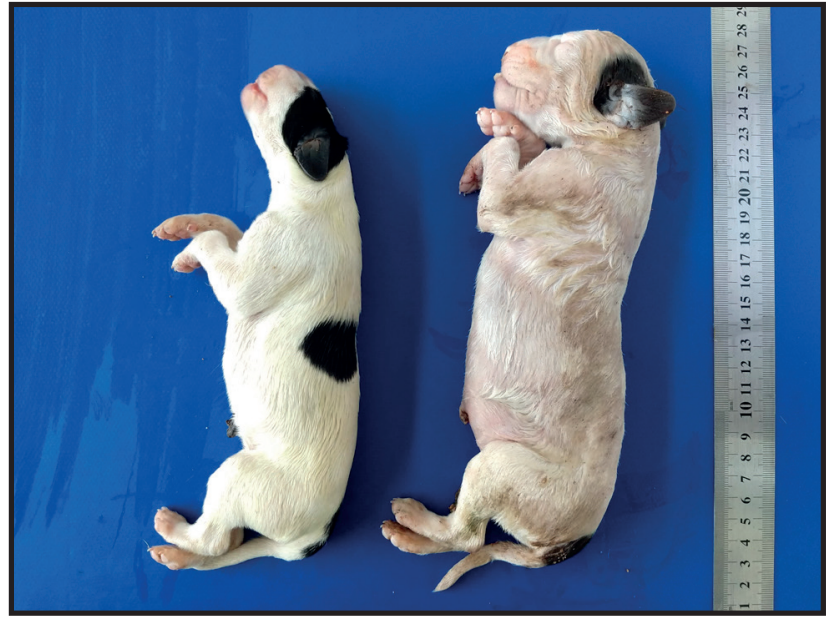

Figure 1. Comparison of puppies from the same litter.

\section{CASE}

Two-day-old English Pointer breed, weighing $278 \mathrm{~g}$, was referred for a necropsy with his brother, weighing $471 \mathrm{~g}$ (Figure 1). They belonged to a litter of 8 puppies, and only one animal presented malformation. The other brother of the litter died after being crushed by the bitch and was sent for comparative and confirmatory causes of death. Clinically, the malformed neonate, for a period of two days until death, presented apathy, crying, opisthotonus, and sucking reflex. The necropsy was performed at the Veterinary Oncology-Pathology Service of the Federal University of Pelotas (SOVET-UFPEL). The newborns were referred to without any refrigeration process. Macroscopic analysis, weighing and morphometry were performed, and during the necropsy, the samples of organs and swabs were collected for histopathological, bacteriological, parasitological and other examinations, if necessary.

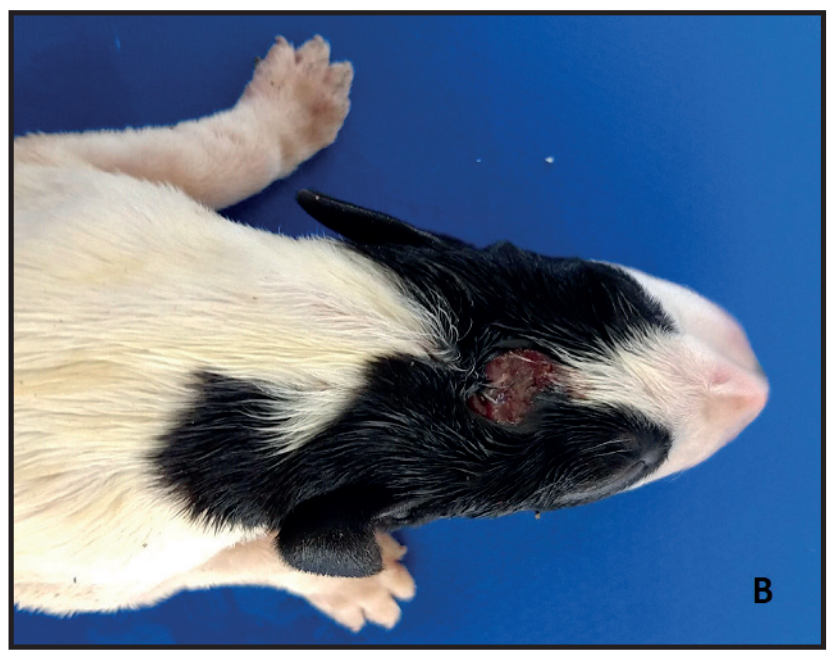




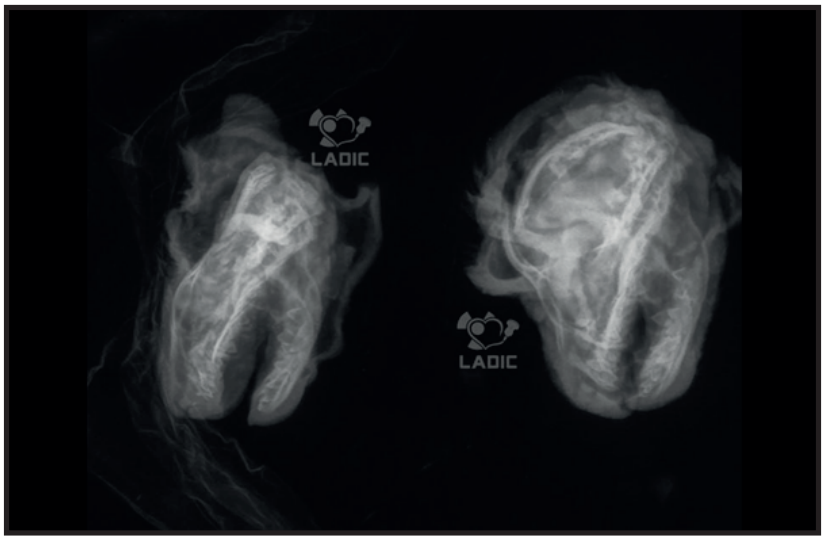

Figure 3. Radiographic image of the newborn's head. Flattening of the parietal bones and no formation of the skull.

The tissue fragments were fixed in $10 \%$ buffered formalin for histopathological examination and were subsequently cleaved, routinely processed and cut in a 3-micron microtome, stained with hematoxylin and eosin and then evaluated under light microscopy.

At necropsy, the malformed neonate presented skull flattening without fusion of the skull bones, meningeal exposure, and no skin closure at the lesion site (Figures 2 A \& B). The heads were radiographed for

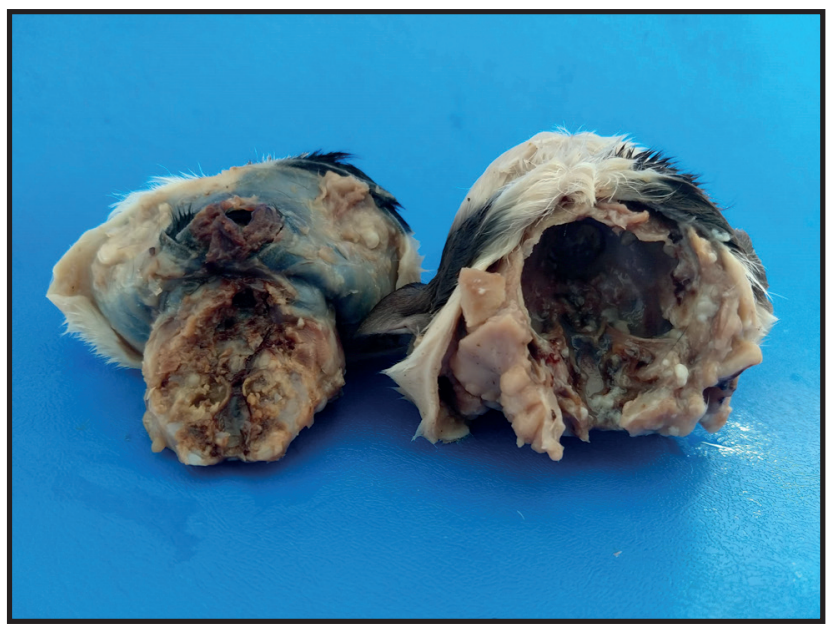

Figure 4. Cranial cavities after brain removal.

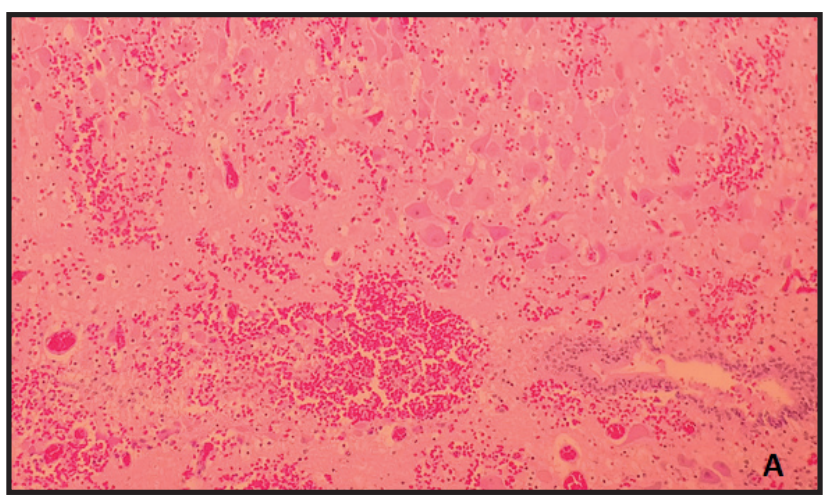

comparison and understanding of the lesion (Figure 3), and the malformed newborn skull flattening was observed. Upon opening the cranial cavity of the affected neonate, the parietal bones were observed to be thickened, with failure of symphysis fusion (dysraphia), and the presence of an irregular, reddish and soft mass was also revealed (Figures $4 \& 5$ ). Histologically, this mass was equivalent to the area cerebrovasculosa, composed of rudimentary glial tissue and vascular neoformation, with hemorrhage and congestion (Figure 6). It was not possible to observe the cranial nerves. The newborn had no other macroscopic changes. There was disorganization of the brain areas with no limitation of white and gray matter and scarce neurons (Figure 7). There was a region similar to the cerebellum, with a molecular layer but without the Purkinje neurons. In the spinal cord also, scarce neuronal tissue and disorganization of gray and white matter were noticed (Figure 8).

\section{DISCUSSION}

In dog embryos, the formation of the neural plate and the cephalic process occurs on days 21 to 22

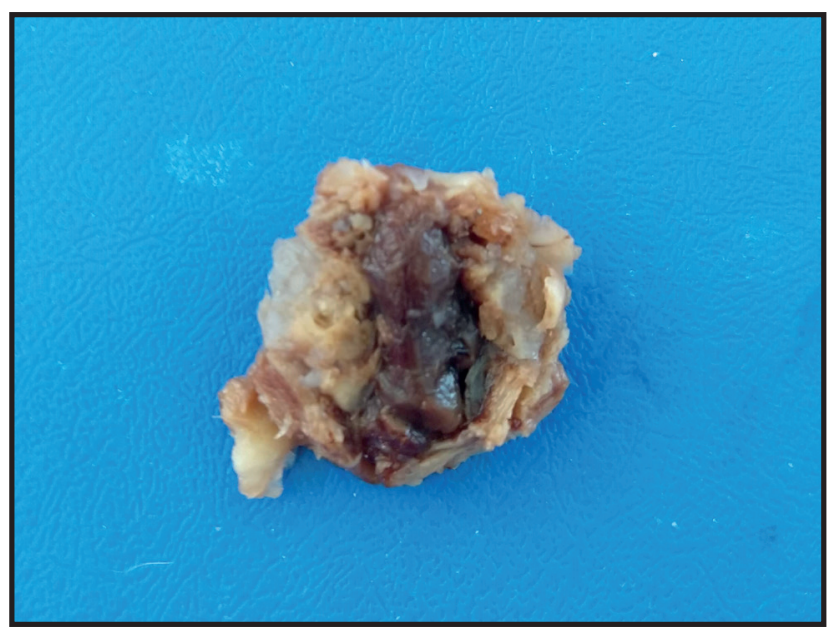

Figure 5. Deformed and reddish mass, equivalent to the brain.

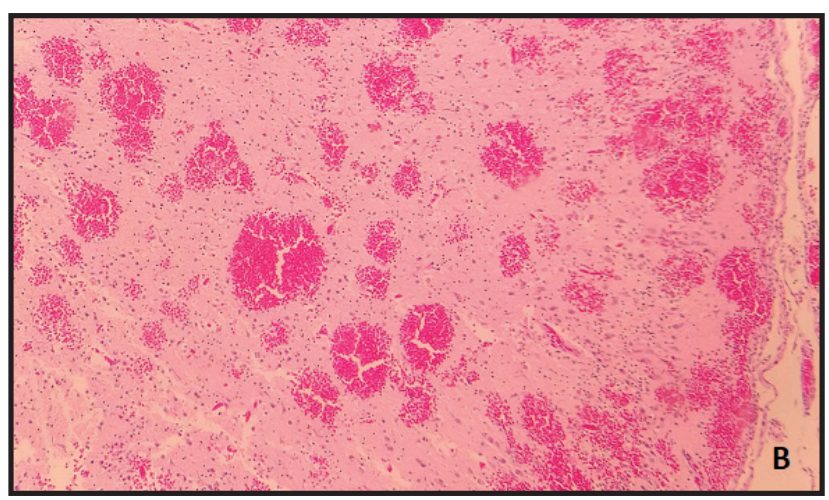

Figure 6. A and B-Area cerebrovasculosa: rudimentary brain with neovascularization [HE; 4x]. 

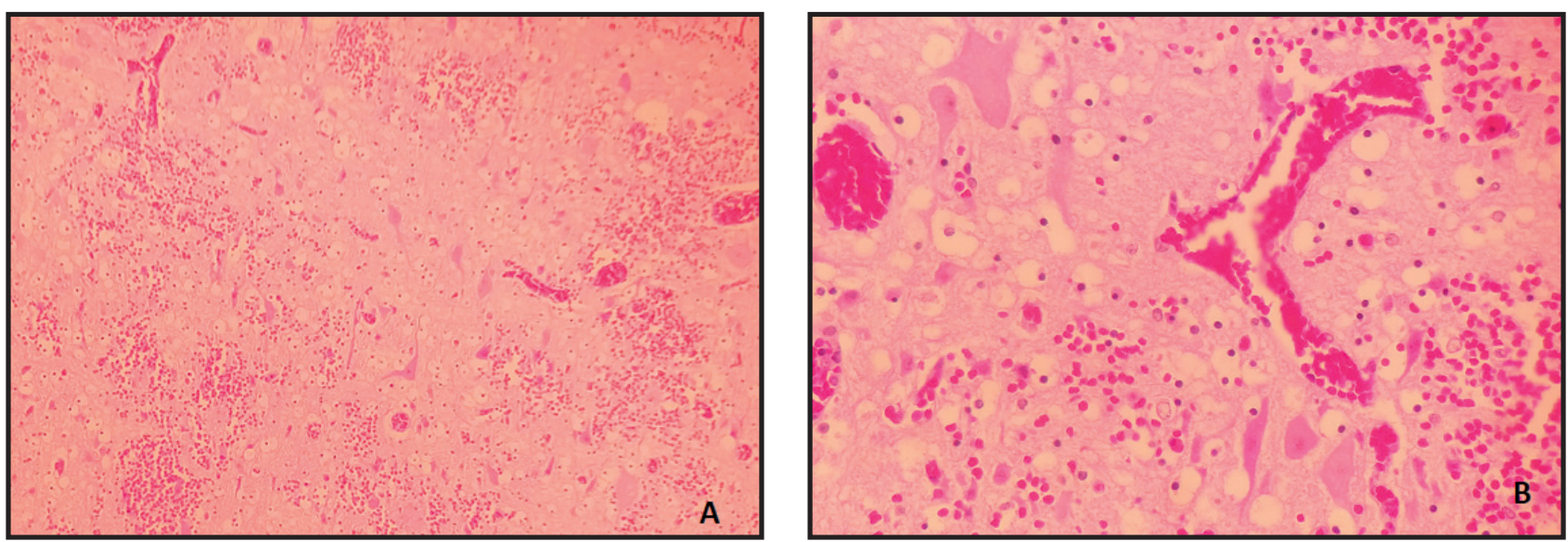

Figure 7. A- Scarce viable neurons and poor white and gray matter delimitation [HE; 10x]. B- Detailing [HE; 40x].
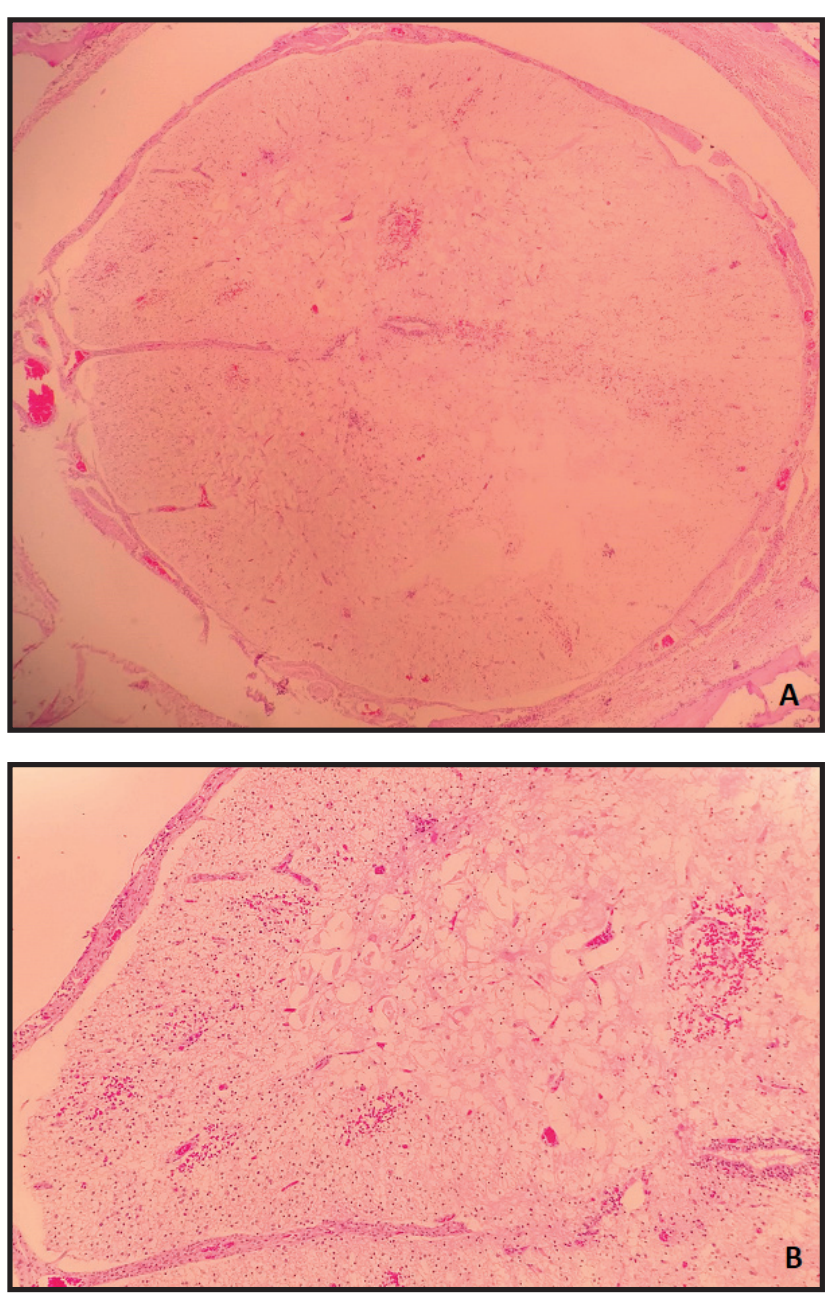

Figure 8. A- Spinal cord with scarce neuronal tissue and gray and white matter clutter [HE; 4x]. B- Detailing [HE; 40x].

of gestation [11]. The neural tube develops from the neural plate $[1,3,5]$, and the brain vesicles form the forebrain, midbrain and rhombencephalon between gestational days 22 to 25 [11]. The formation of the nervous system depends on the fusion of the neuroepithelium with the midline of the neural tube, where closure occurs at various sites along the craniocaudal axis $[2,3]$. Anencephaly develops by default in the cranial portion of the neural tube [5]. Meroanencephaly is a classification among anencephaly [4]. Anencephaly results from a failure of closure of the rostral neuropore (neural crest), and consequently the development of the calvary becomes defective $[5,15]$.

Epidemiological studies have found a high correlation between folic acid deficiency and the incidence of anencephaly and other defects in neural tube closure in humans [12]. In veterinary medicine, data on teratogenic agents are scanty but it is believed that nutritional deficiencies are determining factors for the occurrence of such malformations. Studies about anencephaly in dogs reveal that canine herpesvirus (CaHV-1 type 1) and the use of some drugs during pregnancy are the major causes of this condition [9].

Anatomical conformations concerning the formation of nervous tissue, typically, the absence of skull bone space, and the presence of traces of the brain with acrania (absence of epicranium) are common [8]. Contrary to the findings of this study, some authors agree that no formation of the encephalon, as well as failure in the formation and closure of the skull, is easier to find $[9,15]$. Some other studies report anencephaly/ meroanencephaly, but provide little data regarding macroscopic and especially microscopic findings [4,15]. However, Veiga et al. [14], described similar aspects, but in contrast to the results of the current report, the presence of brain mass was not reported. In our study, it was observed that the cranial cavity was filled with disorganized rudimentary nervous tissue and the vascular spaces were apparently enlarged. These structures can be interpreted equivalently to the area cerebrovasculosa, described in many cases of human 
anencephaly $[2,3,15]$. Thus, we infer that the most appropriate classification for the changes noticed in this study, is meroanencephaly, where there is a presence of neural tissue. It is difficult to identify the real cause of the anencephaly, once the etiology is multifactorial in cranial and encephalic malformations [9].

The present report highlights that pathological changes are not often described in neonates, including malformations, since post mortem pathological examination is rarely requested. It also enhanced the necessity for studies regarding malformations and congenital disorders in dogs since losses can be avoided and/or decreased, and the possibility of infectious agents being involved in the lesions can be investigated. Studies in dogs are still scarce even with canine neonatology in Brazil growing into an important economic and social activity, and being directly linked to Brazilian homes since dogs are considered as family members.

Acknowledgements. We thank the Coordination of Improvement of Higher Education Personnel (CAPES, Brasília, DF, Brazil). The researchers, A.S. Varela Junior (310327/2018-0) and C.D. Corcini (310203/2018-0) thanks CNPQ for the productivity guaranteed.

Declaration of interest. The authors report no conflicts of interest. The authors alone are responsible for the content and writing of the paper.

\section{REFERENCES}

1 Casal M. 2016. Congenital and genetic diseases of puppies before the weaning: can we prevent them? In: VIII International Symposium on Canine and Feline Reproduction (Paris, France). p.46.

2 Copp A.J., Brook F.A., Peter Estibeiro J., Shum A.S. \& Cockroft D.L. 1990. The embryonic development of mammalian neural tube defects. Progress in Neurobiology. 35(5): 363-403.

3 Copp A.J., Greene N.D. \& Murdoch J.N. 2003. The genetic basis of mammalian neurulation. Nature Reviews Genetics. 4(10): 784-793.

4 Dahmer D.A., Chiarentin D. \& Voitena J.N. 2012. Anencefalia em cão: relato de caso. Revista Científica Eletrônica de Medicina Veterinária. 18: 1-6.

5 Huisinga M., Reinacher M., Nagel S. \& Herden C. 2010. Anencephaly in a German Shepherd Dog. Veterinary Pathology. 47(5): 948-951.

6 Leroy G. \& Baumung R. 2011. Mating practices and the dissemination of genetic disorders in domestic animals, based on the example of dog breeding. Animal Genetics. 42: 66-74.

7 Lourenço M.L.G. 2015. Cuidados com neonatos e filhotes. In: Jericó M.M., Kogika M.M. \& Andrade Neto J.P. (Eds). Tratado de Medicina Interna de Cães e Gatos. Rio de Janeiro: Guanabara Koogan, pp.1153-1481.

8 Moore K.L., Pesaud T.V.N. \& Torchia M.G. 2013. Defeitos congênitos do encéfalo. In: Embriologia Clínica. 9.ed. São Paulo: Elsevier, pp.414-422.

9 Nonato I.A., Ferreira M.R., Miranda J.L., Braz H.M.B. \& Machado J.P. 2019. Cranioschisis and Anencephaly in a Dog - Challenging Etiology. Acta Scientiae Veterinariae. 47(Suppl 1): 449.

10 Peterson M.E. 2011. Neonatal Mortality. In: Peterson M.E. \& Kutzler M.A. (Eds). Small Animal Pediatrics. Saint Louis: Elsevier, pp.82-87.

11 Pieri N., Souza A.F., Casals J.B., Roballo K., Ambrósio C.E. \& Martins D.S. 2015. Comparative Development of Embryonic Age by Organogenesis in Domestic Dogs and Cats. Reproduction of Domestic Animals. 50(4): 625-631.

12 Santos L.M.P. \& Pereira M.Z. 2007. Efeito da fortificação com ácido fólico na redução dos defeitos do tubo neural. Caderno de Saúde Pública. 23(1): 17-24.

13 Souza T.D., Mol J.P.S., Paixão T.A. \& Santos R.L. 2017. Mortalidade fetal e neonatal canina: etiologia e diagnóstico. Revista Brasileira De Reprodução Animal. 40(2): 639-649.

14 Veiga C.C.P., Souza B.G. \& Vieira S.L. 2013. Avaliações pré-natal ultrassonográfica e radiográfica no diagnóstico de anencefalia em cão - relato de caso. Revista Brasileira de Medicina Veterinária. 35(2): 101-104.

15 Wammes J.C.S., Filadelpho A.L., Birck A.J., Peres J.A., Pinto e Silva J.R.C., Guazzelli Filho J. \& Barcelos R.P. 2013. Anencefalia, macroglossia e fenda labial em cão: Relato de caso. Revista Científica Eletrônica de Medicina Veterinária. 21: 1-8. 